\title{
Grupos colaborativos na formação de professores: uma revisão sistemática de trabalhos brasileiros
}

\section{Collaborative groups in teacher education: a systematic review of Brazilian studies}

\author{
Maria Aparecida Vilela Mendonça Pinto Coelho ${ }^{1}$
}

\begin{abstract}
Resumo
Este estudo está inserido no grupo de trabalhos da segunda fase do projeto "Mapeamento e estado da arte da pesquisa brasileira sobre o professor que ensina Matemática", que visou mapear as pesquisas brasileiras produzidas no período de 2001 a 2012, cujo foco de estudo é o professor que ensina Matemática. Busca compreender o grupo colaborativo, suas potencialidades e limites para a formação do professor que ensina Matemática e tomou como corpus de análise seis dentre as pesquisas - mapeadas no período - que têm o grupo como objeto e foco principal de estudo. A metodologia utilizada foi a revisão sistemática, que reúne pesquisas dos estudos selecionados e discute os resultados, com o objetivo de elaborar uma metassíntese. Concluiu-se que o grupo colaborativo tem potencial para promover o desenvolvimento profissional do professor, sendo uma boa alternativa para sua formação.
\end{abstract}

Palavras-chave: "grupos colaborativos”, "formação do professor”, "revisão sistemática”, "metassíntese”

\begin{abstract}
This study is part of the work group of the second phase of the project "Mapping and state of the art of Brazilian research on the teacher teaching mathematics", which aimed to map the Brazilian researches produced between 2001 and 2012, whose focus is the Teacher who teaches Mathematics. It seeks to understand the collaborative group, its potentialities and limits for the formation of the teacher who teaches Mathematics, and took as corpus of analysis six of the surveys - mapped in the period - that have the group as object and main focus of study. The methodology used was the systematic review, which gathers researches of the selected studies and discusses the results, with the purpose of elaborating a metassynthesis. It was concluded that the collaborative group has the potential to promote the professional development of the teacher, being a good alternative for its formation.
\end{abstract}

Keywords: "collaborative groups", "teacher training", "systematic review”, "meta-synthesis"

\section{Introdução}

O balanço da pesquisa brasileira realizado no período de 1978 a 2002 (Fiorentini et al., 2002) constatou a emergência e o crescimento das pesquisas que têm como objeto de investigação os grupos e as práticas colaborativas. Foram relacionadas 14 pesquisas que investigaram o processo de formação ou de desenvolvimento profissional do professor em grupos colaborativos ou em trabalhos de parceria com pesquisadores, em um total de 51 trabalhos que investigaram a formação continuada. Segundo os autores, os estudos revelaram

\footnotetext{
${ }^{1}$ Doutora em Educação Matemática pela Universidade Estadual de Campinas, Professora da Universidade Paulista, Brasil. Email: cidapintocoelho@gmail.com
} 
DOI: http://dx.doi.org/10.20396/zet.v25i2.8647600

que os professores se tornaram mais reflexivos em suas práticas, buscaram melhores condições profissionais e se tornaram produtores de seus próprios materiais. E levaram à conclusão de que "há fortes indícios de que o trabalho colaborativo é fundamental para o desenvolvimento profissional dos professores" (Fiorentini et al., 2002, p. 13).

Em estudo mais recente - "Mapeamento e estado da arte da pesquisa brasileira sobre o professor que ensina Matemática" ${ }^{2}$, com o objetivo mapear as pesquisas brasileiras, produzidas no período de 2001 a 2012, que têm como foco de estudo o professor que ensina Matemática (PEM), identificamos um número ainda pequeno de pesquisas voltadas para os trabalhos colaborativos, o que pode sugerir a existência de um campo aberto a novos estudos e a necessidade de um aprofundamento que possa gerar melhor compreensão do tema.

O objetivo desta pesquisa é compreender o grupo colaborativo, suas potencialidades e seus limites para a formação do professor que ensina Matemática, através das pesquisas que têm o grupo como objeto e foco principal de estudo, mapeadas no período de 2001 a 2012. Pretendemos produzir um estudo de segunda ordem, ou seja, colocar em destaque os achados das pesquisas em análise, para que sejam discutidos conjuntamente e confrontados, facilitando maior compreensão do tema e novas inferências.

$\mathrm{Na}$ seção seguinte uma breve discussão teórica sobre as práticas colaborativas na formação de professores será seguida de um esclarecimento sobre a metodologia utilizada no estudo, da análise e síntese das evidências encontradas, destacando como as pesquisas brasileiras que fazem parte do grupo de trabalhos escolhidos investigam e concebem os grupos colaborativos na formação de professores que ensinam matemática.

\section{As práticas colaborativas na formação de professores}

Na metanálise de estudos brasileiros realizada por Passos et al. (2006, p. 6), uma investigação sobre o desenvolvimento profissional do professor que ensina matemática foi conduzida com o objetivo de responder à questão: "Que práticas vêm se revelando catalisadoras do desenvolvimento profissional?". As conclusões do estudo colocaram em evidência as práticas "nas quais o professor passa a se constituir no principal protagonista de sua cultura profissional e de seu desenvolvimento docente" (Passos et al., 2006, p. 34). Foi reconhecido, porém, que tais práticas exigem condições materiais de trabalho, entre elas o reconhecimento dos grupos de estudo dentro das escolas como práticas de formação contínua, em substituição aos programas de "capacitação" impostos aos professores pelas políticas públicas com base nos modelos neoliberais. $\mathrm{O}$ estudo produziu também uma síntese sobre os conceitos de formação e desenvolvimento profissional:

\footnotetext{
${ }^{2}$ Fiorentini, D., Passos, C. L. B. \& Lima, R. C. R. (Org.). (2016). Mapeamento da pesquisa acadêmica brasileira sobre o professor que ensina Matemática: Período 2001 a 2012 (1a ed.). Campinas: FE-Unicamp. Retirado em dezembro de 2016, de[https://www.fe.unicamp.br/biblioteca/e-book- mapeamento-pesquisa- PEM].
} 
DOI: http://dx.doi.org/10.20396/zet.v25i2.8647600

consideramos a formação docente numa perspectiva de formação contínua e de desenvolvimento profissional, pois a mesma pode ser entendida como um processo pessoal, permanente, contínuo e inconcluso que envolve múltiplas etapas e instâncias formativas. Além do crescimento pessoal ao longo da vida, compreende também a formação profissional (teórico-prática) da formação inicial - voltada para a docência e que envolve aspectos conceituais, didático-pedagógicos e curriculares - e o desenvolvimento e a atualização da atividade profissional em processos de formação continuada que acontece após a conclusão da licenciatura. A formação contínua, portanto, é um fenômeno que ocorre ao longo de toda a vida e que acontece de modo integrado às práticas sociais e às cotidianas escolares de cada um, ganhando intensidade e relevância em algumas delas [destaques no original]. (Passos et al., 2006, p. 195)

De acordo com os autores, a formação do professor se realiza de modo integrado às práticas sociais e às suas práticas cotidianas escolares, através de múltiplas instâncias, e envolve aspectos diversos. Essa formação - para nós, um movimento contínuo, de dentro para fora -, parte sempre do próprio professor e não pode ser um treinamento planejado, realizado por instâncias superiores e imposto a ele como um ato de "formar", no sentido de "mudar a forma". Principalmente porque entender a formação docente a partir dessa perspectiva significa acreditar que a atuação do professor é puramente técnica, e consiste em executar regras preestabelecidas por outros, o que não corresponde à complexidade do trabalho docente.

O movimento de formação contínua de professores foi analisado com detalhes por Fullan e Hargreaves (2000, p. 15), que assim opinam: "Simplesmente não há oportunidades nem encorajamento suficiente para os professores atuarem em conjunto, para aprenderem uns com os outros e para melhorarem sua qualificação como uma comunidade". E destacam o isolamento profissional como limitador do acesso a novas ideias e soluções e às mudanças necessárias à escola. Então, concluem que o problema não é um, mas são vários. Citamos alguns: o conservadorismo e a resistência à inovação no ensino; os professores iniciantes sem apoio; os diretores que são, em muitos casos, burocratas; as tendências aos modismos e às soluções rápidas; a pressão, por parte dos que elaboram as políticas, por resultados imediatos. E mais: realizações importantes de alguns professores passam despercebidas, e as que não dão certo não são corrigidas.

Concordamos com Fullan e Hargreaves (2000, p. 34) que "ensinar não é apenas uma coleção de habilidades técnicas, um pacote de procedimentos, uma porção de coisas que você pode aprender. Técnicas e habilidades são importantes, mas ensinar é muito mais do que isso". A prática pedagógica do professor é complexa e exprime seus valores, suas crenças e sua maneira de ser e de se comunicar. O processo de formação profissional a partir da problematização das práticas pedagógicas é discutido por Cochran-Smith e Lytle (2009, p. 5), que desenvolveram o conceito de "pesquisa da prática"3, que reconhece o professor como produtor de conhecimento e agente das pesquisas produzidas no contexto educacional; contrapõe-se ao conceito do professor como técnico, consumidor, recebedor, transmissor e implementador do conhecimento produzido fora da escola; e estimula a reflexão crítica sobre

\footnotetext{
${ }^{3}$ Practitioner research.
} 
DOI: http://dx.doi.org/10.20396/zet.v25i2.8647600

os sistemas de poder e privilégio e sobre diferenças sociais que predominam nos meios educacionais.

A pesquisa da prática envolve a distinção entre o "conhecimento local", frequentemente desvalorizado devido ao seu uso limitado, e o "conhecimento formal", mais generalizável e, portanto, aplicável em contextos mais amplos e publicamente. O conhecimento gerado nas pesquisas da prática, denominado por Cochran-Smith e Lytle (2009, p. 127) "conhecimento local da prática", influencia a ação local, mas contém estruturas interpretativas e teorias da prática úteis também em outros contextos. Nesse sentido, eventos locais têm tendências e efeitos globalizadores, e os saberes profissionais dos professores são valorizados por serem produtores de conhecimento.

O saber profissional dos professores é considerado por Tardif (2002) como um saber plural, formado pelo amálgama de saberes adquiridos na formação profissional e de saberes disciplinares, curriculares e experienciais, desenvolvidos pelos próprios professores e baseados em seu trabalho cotidiano e no conhecimento do seu meio. São saberes denominados práticos, brotam da experiência e são por ela validados. De forma diferente das práticas do cientista e do técnico, segundo o autor, não existem modelos para orientar essa prática, pois "no exercício cotidiano de sua função, os condicionantes aparecem relacionados a situações concretas que não são passíveis de definições acabadas e que exigem improvisação e habilidade pessoal, bem como a capacidade de enfrentar situações mais ou menos transitórias e variáveis" (p. 49).

Diversos pesquisadores brasileiros têm privilegiado os estudos sobre a formação docente em contextos colaborativos (Ferreira, 2003; Fiorentini, 2004; Nacarato, 2005), em que os professores discutem suas práticas pedagógicas, ressignificam seus saberes, podendo contar com o outro para superar suas dificuldades e se desenvolver profissionalmente, pois as relações são de colaboração: os participantes se engajam em um trabalho conjunto, voluntário, para alcançar metas comuns. Diferentemente, no grupo cujas relações são de cooperação, os participantes trabalham juntos, mas o objetivo - geralmente o de proporcionar ajuda a outros - não é necessariamente de todos e há pouca autonomia para tomar decisões. Portanto, os termos cooperação e colaboração apresentam diferenças significativas:

Na colaboração, cada indivíduo participa na maioria das decisões: escolher a meta, definir as estratégias, definir as tarefas, avaliar o resultado; e o faz consciente de que é algo realmente importante para ele, algo que tanto beneficia o grupo como um todo, quanto a ele diretamente. (Ferreira, 2003, p. 82)

Segundo a autora, a colaboração envolve um grau significativo de parceria voluntária e, no desenvolvimento profissional de professores, tem como característica a ação docente como centro. Fiorentini (2004) tem privilegiado os trabalhos colaborativos em suas pesquisas e destaca o desejo das pessoas de trabalhar e estudar em parceria com outras, resultante de um sentimento de inacabamento e incompletude como profissionais. Essa necessidade é

\footnotetext{
${ }^{4}$ Local knowledge of practice.
} 
DOI: http://dx.doi.org/10.20396/zet.v25i2.8647600

explicitada por Bakhtin (2000) na teoria da enunciação, definida como o produto de indivíduos socialmente organizados que se comunicam através do discurso. Segundo essa perspectiva, a significação é uma característica da condição humana, resultante da dinâmica das relações: nosso pensamento nasce e forma-se em interação com o pensamento dos outros. A formação de sentido se realiza nessa relação: "o fato de ser ouvido, por si só, estabelece uma relação dialógica” (Bakhtin, 2000, p. 357). A relação dialógica é, assim, definida como dois tipos de produções verbais, dois enunciados confrontados um com o outro, que entabulam uma relação de sentido, mediada pela linguagem. A concepção de sentido nas relações interpessoais e dialógicas fundamenta-se no conceito bakhtiniano de "exotopia", conceito-chave do pensamento de Bakhtin, que se refere à visão da outra pessoa (o autor), que vê o personagem do exterior e confere sentido à sua vida. A criação estética exemplifica esse tipo de relação humana na qual uma das pessoas completa a outra e dota-a de sentido.

Consideramos de grande valor o outro - que pode ver aquilo que nós mesmos não podemos - e os trabalhos colaborativos, que têm o poder de potencializar reflexões, compreensões e interpretações. Essa visão "exotópica", que Bakhtin caracteriza também como "excedente de visão", pode apresentar-nos uma nova forma de ver as relações dialógicas, como relações de sentido. Quando duas pessoas olham o mundo, ele é diferente para cada uma delas. Posso ver o outro de uma maneira que ele próprio não pode, e esse excedente constante da minha visão em relação a ele é devido ao lugar que ocupo. De acordo com essa concepção, a assimetria na constituição do grupo pode ser considerada fator de enriquecimento, pois o enunciado proferido por cada elemento representa uma visão diferente e original sobre o tema discutido.

Um ponto relevante na constituição de um grupo de trabalho colaborativo é, a nosso ver, a disposição para estudar e discutir questões referentes à prática pedagógica, guiada pela teoria. Professores da universidade e pesquisadores podem formar, junto com professores escolares, um grupo com diferentes olhares, em que cada um pode contribuir igualmente para o crescimento de todos. As características do grupo e a forma de sua constituição têm forte influência nos trabalhos.

Nacarato (2005, p. 179) destaca o desenvolvimento profissional dos professores a partir do próprio contexto de trabalho:

Há relação entre valores e crenças de uma sociedade e uma cultura e o tipo de desenvolvimento profissional. E essa contextualização intervém também nos diferentes marcos escolares: instituição concreta e ambiente de trabalho. Assim, o desenvolvimento profissional dos professores a partir do próprio contexto de trabalho, vem se mostrando altamente promissor.

Segundo a autora, o grupo constituído na própria escola pode também atender às especificidades locais, de alunos e da comunidade. E pode favorecer o trabalho colaborativo, embora possa também gerar divisões e ressentimentos. Portanto, para trabalhar de modo colaborativo, os participantes devem aprender a lidar com a interferência de conflitos e relações de poder. 
DOI: http://dx.doi.org/10.20396/zet.v25i2.8647600 pesquisa.

$\mathrm{Na}$ seção seguinte apresentaremos os aspectos metodológicos que nortearam a

\section{Aspectos metodológicos}

Conforme já informado aqui, este estudo está inserido no grupo de trabalhos da segunda fase do projeto de pesquisa de âmbito nacional "Mapeamento e estado da arte da pesquisa brasileira sobre o professor que ensina Matemática", coordenado pelo Grupo de Estudos e Pesquisas sobre Professores que Ensinam Matemática (GEPFPM), o qual teve por objetivo mapear as pesquisas brasileiras cujo foco de estudo é o professor que ensina Matemática (PEM), produzidas no período de 2001 a 2012. A constatação da necessidade de novos estudos sobre o trabalho colaborativo, tema considerado relevante, mas ainda pouco explorado, levou-nos à elaboração desta pesquisa.

A metodologia adotada foi a revisão sistemática, que reúne pesquisas e discute os resultados dos estudos primários, para elaborar uma metassíntese. É um método rigoroso, explícito e aberto ao debate, que busca identificar as evidências relativas a um determinado tema, coletadas e sintetizadas em um trabalho mais amplo de pesquisa no campo. A reunião do conteúdo disponível sobre determinado tema pode ajudar a compreender os fenômenos, ampliar o conhecimento e favorecer a sua aplicação na adoção de políticas e práticas, e nas tomadas de decisões (Lopes \& Fracolli, 2008).

O termo "metassíntese" tem sido usado para se referir ao amálgama de estudos individuais, a fim de compreender e explicar as descobertas de um grupo de estudos similares e produzir uma interpretação mais substantiva do que os resultados dos estudos individuais ( Godfrey \& Denby, 2006).

A pesquisa foi orientada pela questão: "Quais as potencialidades e os limites do grupo colaborativo para a formação do professor que ensina matemática?”.

Inicialmente revisamos as fichas produzidas pelas pesquisas em todo o território nacional e encontramos 54 trabalhos caracterizados como "Pesquisa colaborativa ou com grupos colaborativos ou em comunidade de prática" no item "Tipo de pesquisa quanto aos procedimentos", na coluna ali reservada aos "Procedimentos Metodológicos". A análise das fichas e dos resumos dessas pesquisas revelou que 6 trabalhos tomaram o grupo colaborativo como foco principal e objeto de estudo, estudando o grupo e seu funcionamento, suas potencialidades e seus limites; e outros 48 o apresentaram apenas como contexto, pois tinham como focos principais, entre outros, as concepções e os saberes docentes, o processo de ensino-aprendizagem, a aprendizagem e a formação de professores e futuros professores.

Realizamos uma análise mais aprofundada com os seis trabalhos do primeiro conjunto - aqueles que tomaram o grupo como foco principal. As pesquisas escolhidas para compor o novo corpus foram lidas na íntegra, organizadas em tabelas, fichadas e separadas por categorias. O Quadro 1 identifica cada trabalho escolhido, sua questão investigativa e o grupo, com destaque ao nome usado pelo pesquisador para se referir a ele. 
DOI: http://dx.doi.org/10.20396/zet.v25i2.8647600

Quadro 1 - Identificação do trabalho e do grupo

\begin{tabular}{|c|c|c|}
\hline Identificação do trabalho & Questão investigativa & Identificação do grupo \\
\hline $\begin{array}{l}\text { Digiovanni }(2005) \text {. } \\
\text { Mestrado Acadêmico, } \\
\text { UFPR } \\
\text { Entre a sensibilidade e a } \\
\text { razão: múltiplas vozes de } \\
\text { professores de matemática } \\
\text { enunciadas em um processo } \\
\text { reflexivo }\end{array}$ & $\begin{array}{l}\text { Como os professores e as professoras } \\
\text { de Matemática se envolvem em grupos } \\
\text { de estudos de Formação Continuada? } \\
\text { (p. } 9 \text { - não está explícita). }\end{array}$ & $\begin{array}{l}\text { Grupo de Estudos em Educação } \\
\text { Matemática (constituído para a } \\
\text { pesquisa, em parceria com a } \\
\text { Secretaria Estadual de Educação - } \\
\text { SEED) } \\
\text { Onze professoras de Matemática da } \\
\text { rede estadual do Paraná, ensino } \\
\text { fundamental e médio. } \\
\text { Modalidade de pesquisa: narrativa } \\
\end{array}$ \\
\hline $\begin{array}{l}\text { Traldi Junior (2006). } \\
\text { Doutorado em Educação } \\
\text { Matemática, PUCSP, } \\
\text { Formação de professores de } \\
\text { Matemática: identificação } \\
\text { de possibilidades e limites } \\
\text { da estratégia de } \\
\text { organização de grupos } \\
\text { colaborativos }\end{array}$ & $\begin{array}{l}\text { "Quais as possibilidades e dificuldades } \\
\text { para que um grupo de trabalho coletivo, } \\
\text { constituído por formadores de } \\
\text { professores, que lecionam a disciplina } \\
\text { de Cálculo Diferencial e Integral, passe } \\
\text { a trabalhar de forma colaborativa, e } \\
\text { quais saberes docentes desta área de } \\
\text { conhecimento são abordados pelo } \\
\text { grupo?" }\end{array}$ & $\begin{array}{l}\text { Grupo de trabalho do tipo } \\
\text { colaborativo a partir de um grupo } \\
\text { coletivo } \\
\text { Constituído para a pesquisa } \\
\text { Sete professores formadores de uma } \\
\text { instituição de ensino superior } \\
\text { Metodologia tipo Estudo de Caso }\end{array}$ \\
\hline $\begin{array}{l}\text { Miola (2008). } \\
\text { Mestrado Acadêmico, } \\
\text { UFPR } \\
\text { Professores de Matemática } \\
\text { e a produção de objetos de } \\
\text { aprendizagem colaborativa } \\
\text { para o Portal Educacional } \\
\text { da Secretaria de Educação } \\
\text { do Estado do Paraná }\end{array}$ & $\begin{array}{l}\text { "Como se desenvolvem os trabalhos de } \\
\text { um grupo de estudos envolvendo } \\
\text { alunos do curso de Licenciatura em } \\
\text { Matemática, professores de Matemática } \\
\text { atuantes em Rede Pública e o } \\
\text { pesquisador, quando estes têm como } \\
\text { objetivo final a produção de um Objeto } \\
\text { de Aprendizagem Colaborativa, } \\
\text { tratando especificamente de } \\
\text { conceitos geométricos?". }\end{array}$ & $\begin{array}{l}\text { Grupo de trabalho colaborativo } \\
\text { Objetos de Aprendizagem } \\
\text { Colaborativa (OAC) } \\
\text { Portal Dia a Dia Educação } \\
\text { (Secretaria de Estado da Educação). } \\
\text { O Ambiente Pedagógico } \\
\text { Colaborativo (APC) tem como } \\
\text { objetivo fornecer um espaço de } \\
\text { aprendizagem para professores da } \\
\text { rede pública da educação básica do } \\
\text { estado do Paraná. } \\
10 \text { integrantes: } 3 \text { professores da rede } \\
\text { estadual e } 6 \text { alunos do curso de } \\
\text { licenciatura em matemática e o } \\
\text { pesquisador }\end{array}$ \\
\hline $\begin{array}{l}\text { Do discutir e resolver em } \\
\text { Matemática: reflexões } \\
\text { sobre a constituição de um } \\
\text { grupo de estudos entre } \\
\text { educadores matemáticos }\end{array}$ & $\begin{array}{l}\text { "Se os professores já atuantes e os em } \\
\text { formação, em conjunto, em um grupo } \\
\text { de estudos, debatessem a possibilidade } \\
\text { da utilização da resolução de problemas } \\
\text { enquanto estratégia de ensino de } \\
\text { Matemática pautada no } \\
\text { desenvolvimento de grupo de alunos } \\
\text { em sala de aula, isso os motivaria a } \\
\text { estabelecer mudanças em suas práticas } \\
\text { docentes?" }\end{array}$ & $\begin{array}{l}\text { Grupo de estudos com } \\
\text { características cooperativas - } \\
\text { GEDMAT - (Grupo de Estudos } \\
\text { entre Educadores Matemáticos), } \\
\text { criado para a pesquisa. } \\
10 \text { integrantes: } 7 \text { futuros professores, } \\
\text { alunos de um curso de licenciatura } \\
\text { em matemática e } 3 \text { professores } \\
\text { convidados de matemática de } \\
\text { escolas públicas, já atuantes }\end{array}$ \\
\hline $\begin{array}{l}\text { Scheibel (2010). } \\
\text { Mestrado Acadêmico, } \\
\text { UTFPR, Ponta Grossa. } \\
\text { A contribuição das técnicas }\end{array}$ & $\begin{array}{l}\text { "Que tipo de trabalho realizar com os } \\
\text { alunos - futuros professores - para } \\
\text { desenvolver, além das habilidades } \\
\text { conceituais, as habilidades sociais, } \\
\text { afetivas, interpessoais visando a uma } \\
\text { prática pedagógica diferenciada }\end{array}$ & $\begin{array}{l}\text { Grupo cooperativo } \\
\text { A autora é professora formadora de } \\
\text { docentes. } \\
\text { Metodologia de trabalho: técnicas de } \\
\text { dinâmica de grupo - Aprendizagem } \\
\text { Cooperativa }\end{array}$ \\
\hline
\end{tabular}


DOI: http://dx.doi.org/10.20396/zet.v25i2.8647600

\begin{tabular}{|c|c|c|}
\hline $\begin{array}{l}\text { de dinâmicas de grupo para } \\
\text { a formação de docentes de } \\
\text { nível médio do Paraná }\end{array}$ & proativa e inovadora?" & $\begin{array}{l}\text { Sujeitos: } 20 \text { alunas do Curso de } \\
\text { Formação de Professores em nível } \\
\text { pós-médio de uma escola estadual }\end{array}$ \\
\hline $\begin{array}{l}\text { Costa (2011). } \\
\text { Mestrado Profissional em } \\
\text { Ensino de Ciências e Mat., } \\
\text { Universidade Estadual da } \\
\text { Paraíba, Campina Grande. } \\
\text { Colaboração e grupo de } \\
\text { estudos: perspectivas para o } \\
\text { desenvolvimento } \\
\text { profissional de professores } \\
\text { de Matemática no uso de } \\
\text { tecnologia }\end{array}$ & $\begin{array}{l}\text { "Que contribuições a participação em } \\
\text { grupo de estudos, que foi se } \\
\text { constituindo como um grupo de } \\
\text { trabalho colaborativo, pode trazer ao } \\
\text { desenvolvimento profissional de } \\
\text { professores de Matemática no que se } \\
\text { refere ao uso de tecnologia?" }\end{array}$ & $\begin{array}{l}\text { Grupo de estudos - foi se } \\
\text { constituindo como um grupo de } \\
\text { trabalho colaborativo. } \\
6 \text { professores de matemática do } \\
\text { Ensino Fundamental e Médio de } \\
\text { uma escola pública - grupo } \\
\text { organizado para a pesquisa, } \\
\text { participação voluntária de } \\
\text { professores de uma escola pública . }\end{array}$ \\
\hline
\end{tabular}

Fonte: levantamento realizado pela autora

Dos seis trabalhos analisados, dois pesquisadores realizaram a pesquisa em um grupo já existente, como é o caso de Miola (2008), que trabalhou em um portal educacional mantido pela Secretaria de Educação do Estado do Paraná, que visava produzir e publicar um Objeto de Aprendizagem Colaborativa, envolvendo conceitos geométricos. Foi feita uma proposta para descrever e analisar todas as fases do trabalho do grupo, realizando encontros com os participantes, intercalados com as atividades do projeto. E Sheibel (2010), formadora de docentes, trabalhou com o grupo formado pelas alunas da Educação Infantil e das primeiras séries do Ensino Fundamental de um curso de Formação de Professores de nível pós-médio. Os grupos analisados eram formados por professores de uma mesma escola, porém Miola (2008) contou com professores de diversas escolas e alunos de graduação.

A seção seguinte traz a análise dos dados extraídos das pesquisas primárias, ou seja, aqueles que poderão contribuir para uma melhor compreensão das práticas colaborativas na formação dos professores, suas potencialidades e limites.

\section{Interpretando o conjunto das pesquisas primárias}

Reunimos seis pesquisas em um único estudo e buscamos elaborar um conhecimento que represente mais do que a soma das partes, em um trabalho interpretativo a partir de nossa ótica teórica e da elaboração de nossos significados. Os dados analisados permitem ao leitor elaborar suas próprias interpretações a partir dos extratos dos estudos apresentados e criam oportunidade para novos debates e novas significações. Os dados foram agrupados em dois blocos: Características dos grupos e Relações mediadas pela linguagem e os saberes profissionais.

\section{Características dos grupos}

O trabalho de Traldi Jr (2006) narra algumas relações observadas em seu grupo de pesquisa, constituído por sete professores formadores de uma instituição de ensino superior. O tipo de pesquisa quanto aos procedimentos foi identificado como um estudo de caso, por ter analisado o movimento de um grupo denominado "grupo coletivo", que foi se transformando em "grupo colaborativo". 
DOI: http://dx.doi.org/10.20396/zet.v25i2.8647600

A competição foi dominante nos dois primeiros encontros e a negociação e cooperação caracterizaram os encontros seguintes. Em um mesmo encontro os três tipos de relação - competição, negociação e cooperação - aconteceram simultaneamente, com intensidades diferentes. Os primeiros momentos foram marcados por atitudes mais reservadas, em seguida veio a disputa para ganhar a liderança, provocando atitudes competitivas. Finalmente, identificamos um terceiro momento, marcado por certo esvaziamento das discussões. Foi quando sentiram a necessidade de elementos externos. (p. 133)

A primeira manifestação de confiança surgiu no terceiro encontro, quando um dos integrantes explicitou uma dúvida referente ao conceito de limite, o que estimulou a cooperação. Com o decorrer do tempo as divergências foram sendo resolvidas por meio de negociações, uma disposição de argumentar e compreender o ponto de vista do outro. (p. 131)

O pesquisador destaca o momento em que um professor explicitou uma dúvida, estimulando a cooperação entre os participantes. O terceiro momento destacado mostra o esvaziamento do grupo, quando se fez necessária uma mudança nos rumos, com a introdução de um agente externo, de um estudo teórico ou de um trabalho comum.

Traldi Jr. (2006) destaca, como limites a um melhor funcionamento do grupo, a falta de prática na organização das pautas das reuniões, o excesso de impressões pessoais desarticuladas de teorias, uma expectativa falsa de encontrar soluções mágicas no grupo, pouco conhecimento sobre a possibilidade da reflexão sobre a ação como uma estratégia de desenvolvimento profissional e a falta de hábito de pesquisar a própria prática. Como fatores que colaboraram para a transição do trabalho coletivo para o colaborativo, aponta os objetivos comuns dos formadores e a necessidade da troca de experiências e de discussões sobre conhecimentos específicos e didáticos da área.

Sheibel (2010), formadora de docentes da educação infantil e das primeiras séries de Ensino Fundamental de um curso de formação de professores de nível pós-médio, utilizou técnicas de dinâmica de grupo na pesquisa com as futuras professoras, para investigar que tipo de trabalho deve ser realizado para preparar as alunas do curso para práticas inovadoras e fundamentadas em habilidades interpessoais. A pesquisa foi sustentada teórica e metodologicamente pela concepção da Aprendizagem Cooperativa, que promove a ruptura com o modelo de ensino da escola tradicional e requer do professor uma postura epistemológica diferenciada e o domínio dos fundamentos teóricos e metodológicos para trabalhar com o aluno as habilidades sociais. Sheibel narra o movimento do grupo:

Faz-se importante mencionar que o grupo como um todo crescia. No entanto, esse crescimento não ocorria com todas as alunas ao mesmo tempo, visto que são pessoas diferentes, dotadas de experiências, possibilidades e saberes diversos. (p.70)

Porém constatou-se que no início desse trabalho, sem necessidade alguma, as alunas assumiam posturas competitivas, individualistas e excludentes. (p.71)

Diante disso é preciso ter a clareza de que o saber docente vai além da transmissão de conteúdos científicos, técnicos e instrumentais, as atitudes tomadas pelos professores nas salas de aula, o modo de ensinar, avaliar, se relacionar e se comunicar com os alunos são ações altamente formadoras e educativas, influenciando tanto ou mais do que o conteúdo ensinado. (p.72) 
DOI: http://dx.doi.org/10.20396/zet.v25i2.8647600

Ela destaca as diferenças individuais no crescimento do grupo e a necessidade de utilizar a metodologia de trabalhos em grupo nos cursos de formação de professores, para que eles tenham contato com práticas que promovam parcerias de colaboração, aceitação de diferenças e respeito às divergências, pois as práticas pedagógicas vivenciadas por eles como alunos possibilitam estabelecer uma cultura de colaboração que pode influenciar positivamente sua prática. Assim Sheibel (2010) esclarece: "Acredita-se que o trabalho com as Técnicas de Dinâmica de Grupo se apresenta como uma opção metodológica que contribui significativamente para o processo de formação de professores". (p. 73)

Paula (2009) trabalhou com sete futuros professores e três professores atuantes e fundou, juntamente com eles, o GEDMAT. A metodologia de trabalho incluiu o trabalho em grupo e a problematização sobre as relações encontradas. Segundo o pesquisador, o professor deve dar mais ênfase à relação do aluno com o saber e valorizar mais suas construções, estabelecendo a cultura do diálogo. Nesse caso, conhecer matemática não é ponto final, mas o ponto de partida. Paula, (2009), Digiovani (2005) e Traldi Jr, (2006) destacam como característica positiva do grupo a heterogeneidade, e Paula (2009) e Digiovani (2005) indicam o fator tempo como necessário para que as relações de cooperação e colaboração se desenvolvam. Digiovani (2005) trabalhou com o Grupo de Estudos em Educação Matemática, constituído de 11 professoras do ensino fundamental e médio da rede pública estadual do Paraná. Analisou os problemas de relacionamento entre os professores, agravados, segundo ela, pelo isolamento e pelo individualismo percebidos em algumas escolas. Assim se expressam os pesquisadores a respeito de suas pesquisas:

Um aspecto que acabou favorecendo o funcionamento do grupo foi o fato do mesmo ser heterogêneo, tanto em termos de experiência profissional (um a vinte anos) quanto em relação à formação na graduação (Licenciatura em Matemática e Bacharelado) (Traldi Jr, 2006, p. 132).

Pelo contrário, essa variedade de opiniões vem ao encontro do nosso objetivo: discutir essa proposta, e não apresentá-la como um modelo a ser seguido pelos professores, sem questionamentos (Paula, 2009, p. 120).

Sabemos que a confiança e a colaboração são qualidades adquiridas no decorrer de um tempo relativamente longo. [...] Com o tempo, e feitas algumas modificações na organização/divisão das tarefas do grupo, o GEDMAT poderá afirmar-se como um grupo colaborativo (Paula, 2009, p. 114).

Podemos concluir que muito tempo ainda levaremos, enquanto grupo, para que as participantes se coloquem de forma confortável em relação às produções escritas (Digiovani, 2005, p. 38).

Costa (2011) trabalhou em um grupo criado para a pesquisa no próprio local de trabalho com seis professores de matemática de uma escola pública. O grupo foi criado para ser um grupo colaborativo, e o objeto de estudo foi a utilização pedagógica das tecnologias informáticas no ensino da matemática. Como ponto positivo do grupo a pesquisadora destaca o fato de ter provocado discussões mais amplas sobre a Educação e sobre os problemas e desafios vivenciados pelos professores. Costa (2011) e Digiovani (2005) citam o cotidiano escolar como o local preferido para realizar trabalhos colaborativos. Os professores de alguns grupos de estudos consideraram mais proveitosas para sua formação as reuniões dos grupos 
DOI: http://dx.doi.org/10.20396/zet.v25i2.8647600

do que as reuniões pedagógicas ou as técnicas de formação continuada que ensinam "como fazer":

De acordo com a fala de Jailson percebemos que os encontros realizados pelo Grupo de Estudos se constituíram em momentos mais proveitosos, em termos de crescimento e desenvolvimento profissional para os professores do que as reuniões pedagógicas oferecidas pela própria escola e secretaria da educação, ocorridas ao longo do ano letivo. (Costa, 2011, p. 154)

Porém isso [técnicas de formação continuada que ensinam como fazer], isoladamente, não garante que haja, nas professoras envolvidas uma reflexão a partir das ações realizadas se não houver, paralelamente, um espaço de interlocução que venha permitir que se reflita sobre a prática à luz das questões teóricas. (Digiovani, 2005, p. 68)

Os professores questionam os cursos de capacitação que acontecem com repassadores (multiplicadores), pois não atingem os objetivos, não preservam a dinâmica de compartilhar experiências de formação e repassar, efetivamente, as informações recebidas para um grupo maior, em um outro momento de espaço-tempo. (Digiovani, 2005, p. 72)

Os trabalhos de Costa (2011) - que destaca depoimento de professores sobre os aspectos positivos da formação no grupo e sua preferência pelo curso em detrimento das reuniões pedagógicas - e de Digiovani (2005), que revela o questionamento dos professores em relação aos cursos de capacitação, reforçaram a importância das parcerias universidadeescola. Por outro lado, o estudo metanalítico desenvolvido pelo GEPFPM evidenciou que a produção das práticas investigativas e colaborativas dos professores não conta com o suporte necessário para viabilizá-las, pois exigem condições de trabalho "que geralmente são negadas pelas instituições e pelas políticas públicas brasileiras com ingerência de modelos neoliberais" (Passos et al., 2006, p. 34).

Ao analisarmos os trabalhos com essa temática, percebemos que no Brasil, assim como em outros países, não há uma compreensão única sobre os temas trabalho coletivo, grupo colaborativo, cooperação, colegialidade. Essa dispersão, segundo Fiorentini 2004, pode afetar a constituição prática dos grupos e também as metodologias escolhidas para analisá-los (Traldi Jr, 2006). Segundo Lima (2002), parte da dificuldade para pôr em prática a noção de colaboração reside no fato de os próprios docentes darem significados diferentes ao conceito e, muitas vezes, não terem ideias claras sobre o nível de colaboração que querem atingir.

O conceito bakhtiniano de "excedente de visão" pode ajudar-nos a ver as relações dialógicas como relações de sentido, principalmente quando ideias diferentes são confrontadas e problematizadas. De acordo com essa perspectiva, grupos heterogêneos, formados por pessoas com diferentes formas de interpretar as situações, podem oferecer maiores oportunidades de desenvolvimento.

Fullan e Hargreaves (2000, p.76) acrescentam, ainda, que, "pelo fato de as culturas cooperativas não se desenvolverem com rapidez, elas podem ser pouco atraentes aos administradores que buscam expedientes ágeis de implementação”. 
DOI: http://dx.doi.org/10.20396/zet.v25i2.8647600

Nacarato (2005, p.177) analisa um material empírico que reúne fragmentos de reuniões e entrevistas que possibilitaram discutir o trabalho coletivo em uma escola e destaca que ele, embora revele potencialidades para a aprendizagem docente, "por estar inserido num contexto permeado de relações de poder, está sujeito a conflitos e interesses que podem comprometer suas potencialidades". Segundo a autora, a prática está inserida em um contexto social e político sujeito a tensões e conflitos nem sempre discutidos e problematizados.

\title{
Relações mediadas pela linguagem e os saberes experienciais
}

Digiovani (2005) relata que o grupo de estudos favoreceu relações mediadas pela linguagem: contando histórias no grupo, o professor elaborava suas reflexões, pois, ao narrar um acontecimento ou sentimento aos outros, percebia o que não havia notado que sentia ou pensava. Os enunciados nos discursos dos professores do grupo revelaram também aspectos importantes sobre algumas de suas concepções vinculadas ao conhecimento e às relações de poder.

\begin{abstract}
Emerge nos enunciados, de forma explícita e/ou implícita, a ideia de que as soluções vêm de alguém que está no poder, prática social esta que caracteriza uma determinada forma de ser e agir no mundo, configurando-se sujeitos que dependem, muitas vezes, de decisões externas, daquele que está no comando (p. 51).

Os enunciados explicitam atividades pedagógicas que parecem ter sido pensadas a partir de informações ouvidas de outros professores, de leituras que foram realizadas em revistas específicas e de cursos frequentados (p. 66).

O que está em jogo, neste enunciado, é uma discussão epistemológica, de que os nossos conceitos, ditos aqui como ideias, são produzidos pela relação social (Digiovani, 2005, p. 69.)
\end{abstract}

Digiovani (2005) relata que os professores dependem, muitas vezes, de decisões externas e que seus enunciados parecem ser repetições, sem reflexão, de discursos alheios. Essas afirmações evidenciam a necessidade de analisar os saberes dos professores - aqueles que servem de base para o ensino e que os pesquisadores anglo-saxões designam pela expressão knowledge base (Tardif, 2002). Provenientes de fontes diversas, entre eles estão os saberes experienciais dos quais trataremos em seguida.

Miola (2008), Digiovani (2005) e Costa (2011) trabalharam com tendências que valorizam os saberes produzidos pelo professor no exercício da profissão. Eles se constituíram em foco de estudo das pesquisas analisadas. Miola (2008) e seu grupo, que já existia em um portal educacional - o dia a dia educação, no qual podemos encontrar o Ambiente Pedagógico Colaborativo (APC) mantido na internet pela Secretaria da Educação do Estado do Paraná -, visavam produzir e publicar um Objeto de Aprendizagem Colaborativa (OAC), envolvendo conceitos geométricos. Foi feita uma proposta ao grupo de descrever e analisar todas as fases do trabalho, realizando encontros intercalados com as atividades do projeto, inserido em uma política de formação de professores em serviço, que permite a divulgação de saberes próprios de cada professor. O grupo contava com dez integrantes, sendo três professores da rede pública estadual; seis alunos de graduação que contavam com bolsa remunerada, dos quais dois cursavam a disciplina de Prática de Ensino; e o pesquisador.

Zetetiké, Campinas, SP, v.25, n.2, maio/ago.2017, p.345-361.

ISSN 2176-1744 
DOI: http://dx.doi.org/10.20396/zet.v25i2.8647600

Segundo Tardif (2002, p. 48), "pode-se chamar de saberes experienciais o conjunto de saberes atualizados, adquiridos e necessários no âmbito da prática da profissão docente e que não provêm das instituições de formação nem dos currículos". Miola (2008) concluiu que os saberes experienciais necessitam de ser validados e sistematizados em espaços onde ocorra uma troca entre professores:

Concluímos que os saberes experienciais podem auxiliar na produção de um OAC tratando de Geometria. Entretanto, nos alinhamos a Tardif (2002) e Moreira (2004) ao apontar que estes saberes precisam ser explicitados e também questionados, pelos próprios professores e pela pesquisa, a fim de que atinjam um grau de objetividade e clareza. Neste trabalho ficou evidenciado que os saberes experienciais não dão conta de todas as situações que surgem na prática docente, ou seja, eles por si só não permitiram ao professor um desenvolvimento mais completo possível. Nesse contexto, acreditamos que existe a necessidade de espaços onde ocorra uma troca entre professores, além de estudos de aprofundamento (Miola, 2008, p. 97).

Digiovani (2005) destacou em sua pesquisa o efeito inibidor da "voz do saber" de um dos participantes - no caso, a voz dela, autora, considerada a coordenadora do grupo ou a voz de maior valor, embora lutasse para evitar essa condição. Os professores questionaram, em outra ocasião, a falta de receptividade do grupo, quando eles mesmos apresentaram ali um trabalho que desenvolveram:

Naquela ocasião, em função das proposições que encaminhei para o grupo, os debates tornaram-se aparentemente menos intensos, minha voz se apresentou como uma voz do saber e isso dificultou a troca que vinha ocorrendo entre as participantes, fato que constatei durante a nossa atividade e na leitura das transcrições. (p. 76)

Questiona-se: por que, quando apresentamos aos nossos pares alguma coisa que vimos ou fizemos, em termos de experiências, não há receptividade e nos sentimos constrangidas? As causas explicitadas indicam que é em função de não serem valorizadas pelo grupo em que estão inseridas. [...] Ao perceber isso, compreendemos que as professoras não se percebem, geralmente, como produtoras de saberes que sejam importantes, tal como aqueles produzidos pela academia. [...] Entendem que a diferença entre aquele que fala e elas é que os primeiros têm uma prática de escrever sobre as coisas que elaboram. (Digiovani, 2005, p. 72)

A análise de Digiovani (2005) sobre as relações do grupo do estudo realizado revela que os professores desenvolvem saberes a partir de suas práticas pedagógicas, que são de grande valor, mas pouco valorizadas, mesmo por eles próprios. E que é importante o fato de os acadêmicos escreverem sobre os seus estudos.

Digiovani (2005) e Costa (2011) destacam, como ponto positivo para a integração do grupo, produzir conhecimentos para outros lerem e referendarem:

Imaginar uma produção do grupo para ser enviada para outros lerem e referendarem foi, para nós, um fato mobilizador da ação. Podemos afirmar que foi uma produção efetivamente coletiva, um texto produzido pela totalidade do grupo de professoras. (Digiovani, 2005, p. 78)

No geral eles concordaram que um dos pontos mais positivos e vivenciado na prática foi justamente a integração da equipe. Essa integração permitiu a realização de trabalhos importantes realizados em parceria, dos quais podemos citar; a participação 
DOI: http://dx.doi.org/10.20396/zet.v25i2.8647600

do Grupo de Estudos em um evento científico (VI Encontro Paraibano de Educação Matemática - VI EPBEM, realizado em Monteiro, Paraíba. (Costa, 2011, p. 160)

A produção coletiva, conforme relato das pesquisadoras, tem o poder de integrar a equipe; contribuir para que os professores percebam sua capacidade de produzir conhecimento a partir de suas práticas pedagógicas; e, principalmente, a nosso ver, colaborar com as pesquisas em formação de professores, falando do lugar de quem tem muito a contribuir. O conhecimento produzido por professores tem sido alvo de um número considerável de trabalhos que têm como foco a formação de professores.

O conhecimento-da-prática (Cochran-Smith \& Lytle, 1999, 2009) procura romper com a dualidade entre o conhecimento formal e o conhecimento prático, considerando as salas de aula como locais para uma investigação intencional, usando a sua própria prática e a teoria produzida por outros como material para questionamento e interpretação. Em estudo anterior concluímos que as pesquisas dos professores podem levar a uma perspectiva diferente para a prática docente a uma valorização dos saberes profissionais dos professores (Coelho, 2010, p. 177).

\section{Considerações finais}

Procuramos produzir uma síntese com as evidências extraídas das pesquisas analisadas e o resultado foi como se tivéssemos produzido um quadro único, juntando diversas peças. O panorama gerado apresenta os grupos colaborativos na formação de professores como uma peça importante e desejável para ser colocada no quadro, mas que exige, para sustentá-la, um trabalho de base que precisa ser executado por políticas educacionais de valorização da profissão docente; por uma formação inicial que prepare o professor de forma condizente com o trabalho intelectual que ele irá assumir; e uma formação continuada em que ele próprio seja o sujeito - tudo isso aliado a melhores condições de trabalho. A ausência de qualquer elemento nessa base pode limitar as condições do grupo colaborativo como contexto privilegiado na formação de professores.

Nossa análise apontou a importância de considerar o nosso próprio grupo de estudo com suas peculiaridades, como as diferenças no tempo de crescimento, ao invés de tentar moldá-lo segundo um grupo ideal (Fullan e Hargreaves, 2000), pois as características do grupo podem definir suas potencialidades para a formação do professor, e os problemas de relacionamento, muitas vezes, podem ser superados pela negociação e pela aceitação. Os grupos heterogêneos devem ser valorizados, pois oferecem maiores oportunidades para a problematização e o desenvolvimento, como nos assegura Bakhtin (2000).

A importância dos estudos teóricos foi considerada fundamental para a sistematização dos saberes experienciais dos professores, como defende Tardif (2002), e a incorporação de elementos externos revelou-se como um aspecto positivo, por assegurar maiores oportunidades de problematização. Olhares diferentes sobre as práticas pedagógicas podem ser assegurados por grupos provenientes de parcerias com universidades, de acordo com experiências apresentadas por Fiorentini (2004), Nacarato (2005) e Ferreira (2003). Um 
DOI: http://dx.doi.org/10.20396/zet.v25i2.8647600

trabalho comum e produções para serem apresentadas aos pares contribuem para a valorização do trabalho do professor e para que possam trabalhar de forma colaborativa (Cochran-Smith e Lytle, 2009). Contar histórias de vida ou escrever foi destacado como importante para a reflexão e para a sistematização dos saberes experienciais. Partimos do pressuposto de que o trabalho do professor é intelectual e não técnico, e devemos lutar por maiores oportunidades para o estudo e a reflexão (Fullan e Hargreaves, 2000).

As pesquisas analisadas nos levam a concluir que os alunos dos cursos de formação inicial devem ter contato com as técnicas de trabalhos em grupo e com outras vivências de trabalhos colaborativos, pois a cultura da colaboração vai sendo desenvolvida com o tempo. Os saberes experienciais, como afirma Tardif (2002), não se encontram sistematizados em doutrinas ou teorias e inviabilizam uma formação elaborada com a finalidade de preparar o docente para a futura profissão. O próprio professor deve preparar-se, juntamente com seus pares, a partir da problematização da sua prática pedagógica, que é imprevisível e está em constante mutação.

Um trabalho de formação contínua dentro da própria escola é desejável, mas não é fácil de ser viabilizado (Nacarato, 2005), por estar limitado pelas condições da instituição; pelo fator tempo; pelas políticas públicas de formação continuada, que indicam soluções ágeis, mesmo que ineficazes; pelas diferenças individuais; e pelas relações de poder, entre outros fatores.

Foi possível aferir das evidências apresentadas que o grupo colaborativo tem potencial para promover o desenvolvimento profissional do professor e é uma boa alternativa para a sua formação. Destacamos a necessidade da luta por mais valorização e melhores condições de trabalho para os professores.

\section{Referências}

Bakhtin, M. M. (2000). Estética da criação verbal. São Paulo: Martins Fontes.

Cochran-Smith, M., \& Lytle, S. L. (1999). Relationships of knowledge and practice: Teacher learning in communities. Review of Research in Education, (24), 249-305.

Cochran-Smith, M., \& Lytle, S. L. (2009). Inquiry as stance: practitioner research for the next generation. New York: Teacher College Press.

Coelho, M. A. V. M. P. (2010). Os saberes profissionais dos professores: a problematização das práticas pedagógicas em Estatística mediadas pelas práticas colaborativas. Tese de Doutorado em Educação - Educação Matemática. Campinas: Universidade Estadual de Campinas.

Ferreira, A. C. (2003). Metacognição e desenvolvimento profissional de professores de Matemática: uma experiência de trabalho colaborativo. Tese de Doutorado em Educação. Campinas: Universidade Estadual de Campinas. 
DOI: http://dx.doi.org/10.20396/zet.v25i2.8647600

Fiorentini, D., Nacarato, A. M., Ferreira, A C., Lopes, C. S., Freitas, M.T.M., \& Miskulin, R. G. S. (2002). Formação de professores que ensinam Matemática: um balanço de 25 anos da pesquisa brasileira. Educação em Revista, 36, 137-160.

Fiorentini, D. (2004). Pesquisar práticas colaborativas ou pesquisar colaborativamente? In M. C. Borba and J. L. Araújo (Orgs.), Pesquisa qualitativa em Educação Matemática (pp. 47-76). Belo Horizonte: Autêntica.

Fiorentini, D., Passos, C. L. B., \& Lima, R. C. R. (Org.). (2016). Mapeamento da pesquisa acadêmica brasileira sobre o professor que ensina Matemática: Período 2001 a 2012 (1a ed.). Campinas: FE-Unicamp. Disponível em: https://www.fe.unicamp.br/pffe/pf/subportais/biblioteca/fev-2017/e-book-mapeamento-pesquisa-pem.pdf.

Fullan, M., \& Hargreaves, A. (2000). A escola como organização aprendente - buscando uma educação de qualidade. Porto Alegre: Artes Médicas Sul.

Godrey, M., \& Denby, T. (2006). The methodology of systematic reviews: conception of the process. Centre for health and Social Care, Institut of Health Science and Public Research, University of Leeds, UK.

Lima, J. A. (2002). As culturas colaborativas nas escolas. Estruturas, processos e conteúdos. Porto: Porto Editora.

Lopes, A. L. M., \& Fracolli, L. A. (2008). Revisão sistemática de literatura e metassíntese qualitativa: considerações sobre sua aplicação na pesquisa em enfermagem. Texto \& Contexto - Enfermagem, 17(4), 771-778.

Nacarato, A. M. (2005). A escola como locus de formação e de aprendizagem: possibilidades e riscos da colaboração. In D. Fiorentini \& A. M. Nacarato (Eds.), Cultura, formação e desenvolvimento profissional de professores que ensinam Matemática (pp.175-195). São Paulo: Musa Editora.

Passos, C. L. B., Nacarato, A. M., Fiorentini, D., Miskulin, R. G. S., Grando, R. C., Gama, R. P., \& Melo, M. V. (2006). Desenvolvimento profissional do professor que ensina Matemática: uma meta-análise de estudos brasileiros. Quadrante, 15(1-2), 193-219.

Tardif, M. (2002). Saberes docentes e formação profissional. Petrópolis: Vozes.

\section{APÊNDICE 1: Relação dos trabalhos do corpus de análise deste estudo}

Costa, M. L. C. (2011). Colaboração e grupo de estudos: perspectivas para o desenvolvimento profissional de professores de Matemática no uso de tecnologia. Dissertação de Mestrado Profissional em Ensino de Ciência e Matemática. Campinas Grande: Universidade Estadual da Paraíba.

Digiovani, A. M. P. (2005). Entre a sensibilidade e a razão: múltiplas vozes de professores de matemática enunciadas em um processo reflexivo. Dissertação de Mestrado Acadêmico em Educação. Curitiba: Universidade Federal do Paraná. 
DOI: http://dx.doi.org/10.20396/zet.v25i2.8647600

Miola, R. J. (2008). Professores de Matemática e a produção de objetos de aprendizagem colaborativa para o portal educacional da Secretaria de Educação do Estado do Paraná. Dissertação de Mestrado Acadêmico em Educação. Curitiba: Universidade Federal do Paraná.

Paula, E. F. (2009). Do discutir e Resolver em Matemática: reflexões sobre a constituição de um grupo de estudos entre educadores matemáticos. 2009. Dissertação de Mestrado Acadêmico em Educação para a Ciência e a Matemática. Maringá: Universidade Estadual de Maringá.

Scheibel, M. R. (2010) A contribuição das técnicas de dinâmicas de grupo para a formação de docentes de nível médio. Dissertação de Mestrado Profissional em Ensino de Ciências e Tecnologia. Ponta Grossa: Universidade Tecnológica Federal do Paraná.

Traldi Junior, A. (2006). Formação de professores de Matemática: identificação de possibilidades e limites da estratégia de organização de grupos colaborativos. Tese de doutorado em Educação Matemática. São Paulo: Pontifícia Universidade Católica de São Paulo (Programa de Estudos Pós-Graduados em Educação Matemática). 